\title{
Topographic study of $H$. pylori and gastric intestinal metaplasia in patients with dyspepsia in a tertiary health care setting.
}

\author{
Jawahar. R. ${ }^{1}$, Varghese R.G.B. ${ }^{2,}$ Alexander T. ${ }^{3}$, Kurian G. ${ }^{4}$ \\ ${ }^{1}$ Dr. R. Jawahar, Associate Professor, Department of Pathology, Aarupadai Veedu Medical College and Hospital, \\ Puducherry, ${ }^{2}$ Dr. Renu G'Boy Varghese, Professor, Department of Pathology, ${ }^{3}$ Dr. Thomas Alexander, Professor, \\ Department of Gastroenterology, ${ }^{4}$ Dr. George Kurian, Professor, Department of Gastroenterology; ${ }^{2,3,4}$ authors are \\ affiliated with Pondicherry Institute of Medical Sciences, Puducherry, Tamilnadu, India.
}

Correspondence Author: Dr. Renu G'Boy Varghese, Professor, Department of Pathology, Pondicherry Institute of Medical Sciences, Puducherry, India. E-mail: jawahar84@gmail.com

\begin{abstract}
Background \& Objectives: Dyspepsia is a relatively common clinical condition characterized by chronic / recurrent upper abdominal pain or discomfort and is often associated with one or more of following symptoms at any given time upper abdominal pain, burning sensation in the chest or upper abdomen, regurgitation, anorexia and early satiety. The present study was done to estimate the prevalence of Intestinal Metaplasia (IM) in the stomach in unselected patients with dyspepsia and to correlate these changes with symptoms, risk factors and endoscopic findings. Methods: We evaluated 102 patients who presented with symptoms of dyspepsia. Relevant clinical details were noted. A minimum of 9 endoscopic mucosal biopsies were taken from all subjects and in addition, biopsies were also taken from endoscopically abnormal areas. Rapid Urease Test (Standard in-house method) was done. All gastric biopsies were graded according to the Updated Sydney System. Statistical analysis was done using Chi-square test. Results: Intestinal metaplasia (IM) was seen in $16.7 \%$ of the patients, predominantly in the antrum $(10.8 \%)$ and all of them showed Type II IM. Atrophic gastritis was again seen predominantly $(65.2 \%)$ in the gastric antrum and these patients had significantly less $(\mathrm{P}=0.0065) H$. pylori infection. Reflux symptoms were significantly less in patients with IM. Conclusion: We found a prevalence rate of $16.7 \%$ of Type II Intestinal Metaplasia of the stomach, which was topographically preponderant in the antrum.
\end{abstract}

Key words: Dyspepsia, Endoscopy, H. pylori, Intestinal Metaplasia, Rapid Urease Test

\section{Introduction}

Dyspepsia is a relatively common clinical condition characterized by chronic / recurrent upper abdominal pain or discomfort and is often associated with one or more of the following symptoms at any given time upper abdominal pain, burning sensation in the chest or upper abdomen, upper abdominal fullness or bloating, nausea, belching, regurgitation, anorexia and early satiety [1].

Dyspepsia is not only a convenient descriptor for upper GI symptoms, but is also a marker for structural diseases like malignancy, peptic ulcer disease, gastritis etc. In such patients, Upper Gastrointestinal Endoscopy offers the potential for early and precise diagnosis of a structural disease. Of course, after evaluation, in many dyspeptics no structural cause is found and they are labeled as having "Functional Dyspepsia". Intestinal

Manuscript received: $7^{\text {th }}$ May 2019

Reviewed: $17^{\text {th }}$ May 2019

Author Corrected: $24^{\text {th }}$ May 2019

Accepted for Publication: 27 $7^{\text {th }}$ May 2019
Metaplasia (IM) of the stomach is a common finding in patients with dyspepsia. Intestinal metaplasia is defined as the replacement of gastric epithelium by an epithelium that histologically resembles the intestinal mucosa. Several classification systems have been used, but the one most widely employed is that proposed by Jass \& Filipe [2]. According to this classification, intestinal metaplasia is classified into complete and incomplete types. The complete type, or Type I, is characterized by the presence of absorptive cells, Paneth cells and goblet cells secreting sialomucins, which correspond to the small intestine phenotype. The incomplete type, which encompasses Types II and III is characterized by the presence of columnar and goblet cells secreting sialomucins and / or sulphomucins. Type II secretes neutral and acidic sialomucins and Type III produces sulphomucins. Other features associated with Type III intestinal metaplasia include prominent glandular distortion and the absence of Paneth cells [2]. 
A cohort study reported a fourfold increased risk of gastric cancer in individuals with type III IM compared to individuals with type I IM [3]. Though the risk of gastric cancer developing in patients with intestinal metaplasia appears to be higher, studies have not been consistent and there are no established guidelines regarding the management or follow up of patients with intestinal metaplasia.

\section{Materials and Methods}

Study Design: A Prospective study was conducted during the period of November 2009 to March 2012.

Inclusion Criteria: All patients presented to the Gastroenterology department with dyspepsia were included in the study.

Exclusion Criteria: Patients with bleeding disorder and patients on anticoagulant drugs were excluded from the study.

Sample Size: 102 cases were included after applying the exclusion criteria.

Sample Collection: Upper GI endoscopy was performed on selected patients by a single endoscopist using Olympus GIF-H 180 fiber optic gastro duodenoscope, after sedation with IV Midazolam. A minimum of 9 endoscopic mucosal biopsies were taken- 7 gastric biopsies (2 from antrum, 1 from incisura angularis, 2 from body, 2 from cardia, in accordance with the Updated Sydney System recommendation and 2 from the distal esophagus $2 \mathrm{~cm}$ above the $\mathrm{Z}$ line [4]. Additional biopsies were also taken from the endoscopically abnormal areas. Rapid Urease Test (standard in house method) was performed in the Endoscopy room and the results were noted at 1 hour and at 24 hours if the initial reading was negative [5]. The biopsies were fixed in $10 \%$ buffered formalin;

\section{Original Research Article}

routinely processed and embedded in paraffin. The histologic sections were stained with Hematoxylin \& Eosin (H \& E) and Giemsa stain for Helicobacter pylori (H.pylori). In addition Alcian blue stain for mucins was done at varying $\mathrm{pH}(2.5 \& 1.0)$ [6].

All the biopsies were graded for H.pylori and Intestinal Metaplasia using Updated Sydney System of Grading [4]. The histological findings were correlated with the endoscopic and clinical findings at the end of the study.

In this study the presence of H.pylori infection was ascertained by Rapid Urease Test (standard in-house) along with $\mathrm{H} \& \mathrm{E}$ and Giemsa stain. We considered a positive H\&E or Giemsa stain to be the gold standard in diagnosing H.pylori infection. Rapid Urease Test (RUT) for H.pylori was reported as: Rapid Positive $(<1 \mathrm{hr})$, Delayed Positive (1hr-24hrs) and Negative. A positive Alcian blue stain was considered to be the gold standard to diagnose intestinal metaplasia.

Criteria used for a diagnosis of histologic Reflux Esophagitis were: Basal cell hyperplasia more than $1 / 3^{\text {rd }}$ of squamous mucosa, neutrophilic exocytosis, and congested papillae in upper $1 / 3^{\text {rd }}$ of the squamous mucosa and for grading Endoscopic Reflux Esophagitis, the Los Angeles Classification was used [7].

Statistical Methods: Data analysis was done using Statistical Package for Social Sciences Version 17.0 (SPSS 17.0) software. The prevalence of intestinal metaplasia was represented as percentage. All other histopathological findings with endoscopic and clinical findings were compared with Chi Square Test and a 'p' value of $<0.05$ was considered statistically significant.

Ethical Consent: This study was approved by the Institutional ethical committee and research cell.

\section{Results}

In this study involving 102 patients, the mean age was $41.5 \pm 15$ (SD), with a range from 16 to 89 years, predominantly between $31-50$ years $(44 ; 43.1 \%$ ) (Table 1$)$. Males $(55 ; 54 \%)$ out numbered females $(47 ; 46 \%)$ by a ratio of 1.2:1.

Analysis of the symptoms revealed that upper abdominal pain was the most common symptom $(\mathrm{n}=75 ; 73.5 \%)$ while dysphagia was the most infrequent ( $\mathrm{n}=22 ; 21.6 \%)$. Endoscopic abnormalities were detected in $78.4 \%$ of patients.

Among them the commonest abnormality was erythematous gastritis which was seen in 43 patients, followed by duodenal ulcer in 15 patients, erosive gastritis in 14 patients, gastric ulcer in 3 patients, esophageal candidiasis in 4 patients and carcinoma stomach in 1 case.

When the symptom positive patients are compared with the presesnce of Intestinal Metaplasia, around 17 (16.7\%) were IM positive, and $85(83.3 \%)$ were IM negative patients (Figure 1). All of them had incomplete type of intestinal metaplasia (Figure 2). The commonest site of intestinal metaplasia was in the antrum (10.1\%) and in no patient was it found in the body (Table 2). Intestinal metaplasia was significantly $(\mathrm{p}=0.001)$ less in patients greater than 60 years of age as compared to those patients who were less than 60 years. 
Table-1: Age Group Distribution.

\section{Original Research Article}

\begin{tabular}{|c|c|}
\hline Age Group & Percentage \\
\hline$<30 \mathrm{yrs}$ & $29.40 \%$ \\
\hline $31-50 \mathrm{yrs}$ & $43.10 \%$ \\
\hline $51-70 \mathrm{yrs}$ & $23.50 \%$ \\
\hline $71-90 \mathrm{yrs}$ & $4 \%$ \\
\hline
\end{tabular}

Table-2: Various Histopathological Findings.

\begin{tabular}{|c|c|c|c|c|}
\hline \multirow{2}{*}{ Histological Variables } & \multicolumn{4}{|c|}{ Sites of Stomach } \\
\cline { 2 - 5 } & Body & Incisura & Antrum & Cardia \\
\hline H.pylori positivity & $91.9 \%$ & $87.1 \%$ & $82.3 \%$ & $82 \%$ \\
\hline Chronic Inflammation & $100 \%$ & $98 \%$ & $98 \%$ & $100 \%$ \\
\hline Intestinal Metaplasia & 0 & $3 . \%$ & $10.7 \%$ & $3 . \%$ \\
\hline
\end{tabular}

H.pylori- Helicobacter pylori

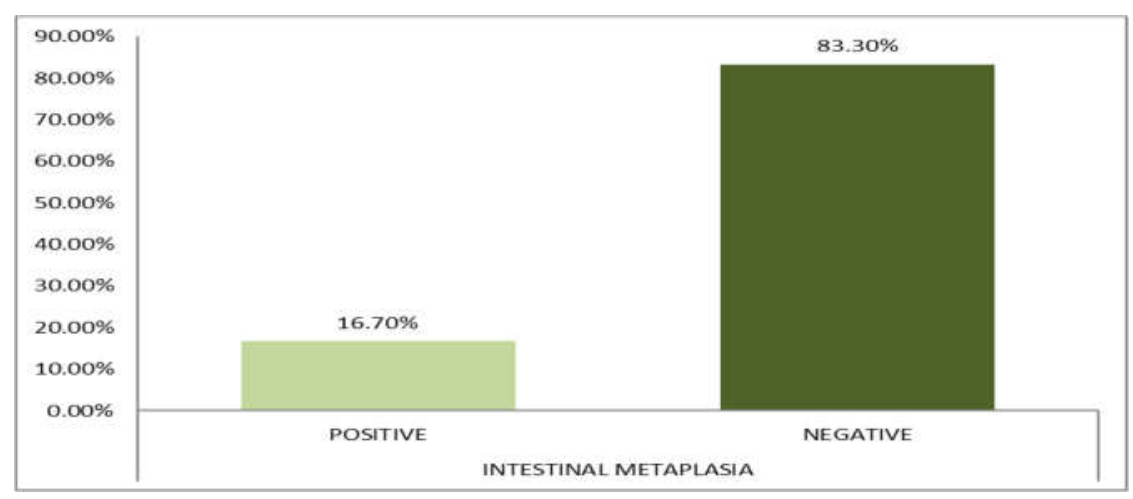

\begin{tabular}{|c|c|c|}
\hline $\begin{array}{c}\text { Symptom Positive } \\
\text { cases }\end{array}$ & $\begin{array}{c}\text { Intestinal Metaplasia } \\
\text { Positive }\end{array}$ & $\begin{array}{c}\text { Intestinal Metaplasia } \\
\text { Negative }\end{array}$ \\
\hline 102 & $17(16.7 \%)$ & $85(83.3 \%)$ \\
\hline
\end{tabular}

Figure-1: Comparison of Dyspeptic Symptoms and Intestinal Metaplasia

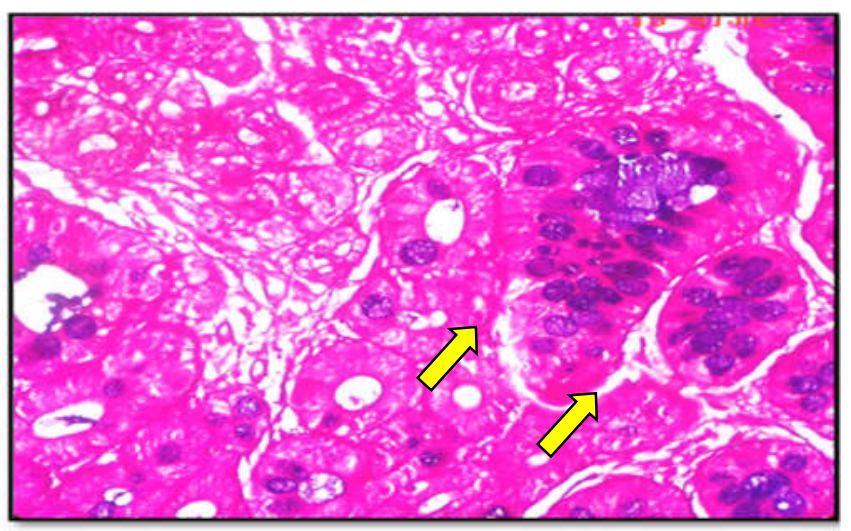

Figure-2: Arrow marks indicate Moderate Degree of Intestinal Metaplasia, (Alcian Blue PAS stain, X100)

Reflux symptoms were significantly less $(\mathrm{p}=0.042)$ in patients with IM as compared to those who did not have IM. 


\section{Original Research Article}

A total of 62 patients were positive for H.pylori on histologic examination. There was $100 \%$ concordance between H\&E staining and Giemsa staining. The concordance rate for RUT and histology for H.pylori was $83.9 \%$. In the present study H.pylori was most commonly located in the body (91.9\%) followed by the incisura $(87.1 \%)$, antrum $(82.3 \%)$ and cardia (82\%) (Table 2).

H. pylori was strongly associated with the presence of chronic gastritis. H.pylori was detected in all patients who had evidence of chronic inflammation in the cardia (62) and corpus (62) and in $98 \%$ of the subjects (61/62) who had chronic inflammation located in the antrum and incisura (Table 2).

H.pylori infection was significantly less $(\mathrm{p}=0.0065)$ in patients with atrophic gastritis. There was no difference $(\mathrm{p}>0.05)$ in the rates of H.pylori infection between those who had and did not have IM. Prevalence of H.pylori positivity was similar among smokers and non-smokers $(\mathrm{p}=0.364)$. On comparing histologic reflux disease with endoscopic evidence of reflux, it was noted that there were $27(90 \%)$ patients who did not have endoscopic reflux but had histological features. The difference in histologic Gastro Esophageal Reflux Disease (GERD) between consumers and non-consumers of alcohol was not significant $(\mathrm{p}=0.93)$. Similarly, smoking did not appear to contribute to histologic GERD $(\mathrm{p}=0.99)$.

\section{Discussion}

Our study revealed that the prevalence of IM was $16.7 \% \quad(17 / 102)$ among unselected adults with dyspepsia. This is well in keeping with the prevalence rates detected in much larger studies. A study done in India by Prabhu et al also showed IM in $4 \%$ of patients with non-ulcer dyspepsia [8]. Another recent study done by Zullo et al found IM in $29.5 \%$ of patients with non-ulcer dyspepsia [9]. Odzin et al in a study conducted at Turkey, had found a similar prevalence of IM in 586 patients (17.8\%) among a total of 3301 consecutive adult dyspeptic patients [10].

In our study IM was predominantly found amongst the middle aged subjects (mean age 53.2). However, because of relatively less number of patients in the study, above the age of 60 years, IM was significantly $(p=0.0015)$ more common in those aged less than 60 year, and the most common location was in the antrum $(10.8 \%)$. Cassaro et al had also found IM predominantly in the antrum (23\%) among patients with non ulcer dyspepsia [11]. However, the mean age of this group of patients with IM was a decade younger (42 years).

In our present study, a total of 62 patients were positive for H.pylori on histologic examination. There was $100 \%$ concordance between $\mathrm{H} \& \mathrm{E}$ staining and Giemsa staining and the concordance rate for our standard in house RUT and histology for H.pylori was $83.9 \%$. There were 9 patients who were RUT positive and histology negative and 10 patients who were histology positive but RUT negative. Goh KL had studied Rapid Urease Test in the diagnosis of H.pylori infection in 274 gastric biopsy samples and compared it with histologic techniques. He found that histology had the highest sensitivity of $99.3 \%$ followed by the RUT $96.6 \%$, but false negative results were inevitable in histological technique because of the patchy distribution of bacteria [12].
In the present study H.pylori was most commonly located in the body (91.9\%), followed by the incisura $(87.1 \%)$, antrum $(82.3 \%)$ and cardia $(82 \%)$.

Mishra et al had performed a topographic study of H.pylori density, distribution and associated gastritis in 50 patients who had H.pylori infection.

They took biopsies from antral lesser curvature, antral greater curvature, and the lesser and greater curvature of the corpus. Among these patients H.pylori was predominantly distributed in the lesser curvature of the antrum (82\%; 41 patients). Furthermore $80 \%$ (40) of subjects had predominantly antral gastritis and $16 \%$ had pangastritis [13].

In the present study too H.pylori was strongly associated with the presence of chronic gastritis. $100 \%$ of patients with the infection had chronic inflammation in the cardia and corpus and $98 \%$ in antrum and incisura. H.pylori is the single most important cause of chronic gastritis; with other causes being chronic irritants like, caffeine, alcohol, tobacco; stress and dysregulated immunity etc [14].

In our study the prevalence of H.pylori infection in patients with non atrophic gastritis was significantly greater $(\mathrm{p}=0.0065)$ when compared with those who had atrophic gastritis.

Zhang $\mathrm{C}$ et al in their study found that H.pylori infection was strongly related to glandular atrophy, IM and gastric ulcer. They noted that among the H.pylori infected, individual glandular atrophy was seen in $50.7 \%$ of patients with superficial gastritis, $76.1 \%$ patients with erosive gastritis, $84.4 \%$ patients with gastric erosion, $80.6 \%$ patients with gastric ulcer and in $85.5 \%$ patients with early gastric cancer [15]. 
Our study also showed that $29.4 \%$ of dyspeptic patients had changes of GERD at histology. In this group 90\% $(27 / 30)$ had a normal esophagus at endoscopy. In an article published in the American Journal of Surgical Pathology, Riddell had found that $50 \%$ of healthy persons had histologic evidence of GERD when biopsies were taken from the distal $2-3 \mathrm{~cm}$ of esophagus [16].

The increased frequency of histologic changes in our study was found despite using a stricter definition of histologic esophagitis (basal cell hyperplasia + neutrophilic exocytosis + congested papillae in the upper one third of mucosa). This disparity, might have been due to proton pump inhibitor (PPI) intake by $43.3 \%(13 / 30)$ of patients in this group (endoscopy negative, histology positive), since it is well known that, after treatment with acid suppressants, endoscopic healing of GERD could occur without histologic healing.

\section{Conclusion}

We found Intestinal Metaplasia of the stomach to be present in $16.7 \%$ of unselected patients with dyspepsia and interestingly all of them were Type II (In complete type) Intestinal Metaplasia. Furthermore H.pylori was most often detected in the body. In addition, we also found histological evidence of GERD in quite a few patients who did not have endoscopic features of GERD.

Hence, surveillance by endoscopy may be indicated in those with extensive Intestinal Metaplasia or those with incomplete type Intestinal Metaplasia, particularly in populations with high Gastric Carcinoma risk. However a large randomized, prospective, multicenter study is desperately needed to characterize the best screening tool as well as the optimal surveillance interval for patients with gastric pre-neoplastic lesions.

\section{What this study adds to existing knowledge?}

- Even though for detecting H.pylori, histology had the highest sensitivity of $99.3 \%$ followed by the RUT $96.6 \%$, but false negative results were inevitable in histological technique because of the patchy distribution of bacteria, hence a prompt review of histopathology is necessary for its detection.

- Endoscopic findings of gastroesophageal reflux disease were correlating with $10 \%$ of patients with GERD histologically. Hence in dyspeptic patients it's advisable to confirm endoscopic findings with histopathology.

\section{Original Research Article}

- Also our study revealed that the prevalence of Intestinal Metaplasia was $16.7 \%$ among unselected adults with dyspepsia. Hence the early detection of Intestinal metaplasia can be used as an indicator for gastric cancer risk which can helps us plan the treatment strategies to reduce the development of gastric cancer.

Author Contribution: The study was jointly conceived by Dr. Renu G'Boy Varghese and Dr. Thomas Alexander. Dr. George Kurian and Dr. Thomas Alexander performed the endoscopic biopsies and reported the clinical findings.

Dr. Renu G'Boy Varghese and Dr. R. Jawahar collected the patient data and reported the histopathology specimens, and did the compilation and interpretation of data.

Dr. Renu G'Boy Varghese has given final review and approval of the drafted article.

Findings: Nil; Conflict of Interest: None initiated Permission from IRB: Yes

\section{References}

1. Feldman M, Friedman LS, Brandt LJ. Sleisenger and Fordtran's Gastrointestinal and Liver Disease. Pathophysiology, Diagnosis, Management. 9th ed. Saunders Elsevier. Philadelphia;2010.

2. Jass JR, Filipe MI. The mucin profiles of normal gastric mucosa, intestinal metaplasia and its variants and gastric carcinoma. Histochem J. 1981 Nov;13(6): 931-9.

3. Filipe MI, Muñoz N, Matko I, et al. Intestinal metaplasia types and the risk of gastric cancer: a cohort study in Slovenia. Int J Cancer. 1994 May 1;57(3): 324-9.

4. Dixon MF, Genta RM, Yardley JH, et al. Classification and grading of gastritis. The updated Sydney System. International Workshop on the Histopathology of Gastritis, Houston 1994. Am J Surg Pathol. 1996 Oct;20(10):1161-81.

5. Pande R, Karki BB. Evaluaton of Locally made Rapid Urease Test for Diagnosis of Helicobacter Pylori. Post-Graduate Medical Journal of NAMS. 2009 Dec 29;9(02):50-53.

6. Bancroft JD, Gamble M, editors. Theory and practice of histological techniques. Elsevier health sciences; 2008. 
7. Zuberi BF, Faisal N, Quraishy MS, Afsar S, Kazi LA, Kazim E. Correlation between clinical, endoscopic and histological findings at esophago-gastric junction in patients of gastroesophageal reflux disease. JournalCollege Of Physicians And Surgeons Of Pakistan. 2005 Dec;15(12):774-7.

8. Prabhu SR, Amrapurkar AD, Amrapurkar DN. Role of Helicobacter pylori in gastric carcinoma. National medical journal of india. 1995 Jan 1;8(2):58-60

9. Zullo A, Hassan C, Romiti A, et al. Follow-up of intestinal metaplasia in the stomach: When, how and why. World J Gastrointest Oncol. 2012 Mar 15;4(3):306. doi: 10.4251/wjgo.v4.i3.30.

10. Ozdil K, Sahin A, Kahraman R, Yuzbasioglu B, Demirdag $\mathrm{H}$, Calhan $\mathrm{T}$, et al. Current prevalence of intestinal metaplasia and Helicobacter pylori infection in dyspeptic adult patients from Turkey. Hepatogastroenterology. 2010;57(104):1563-6.

11. Cassaro M, Rugge M, Gutierrez O, et al. Topographic patterns of intestinal metaplasia and gastric cancer. Am J Gastroenterol. 2000 Jun; 95(6): 1431-8. DOI:10.1111/j.1572-0241.2000.02074.x.

\section{Original Research Article}

12. Goh KL, Parasakthi N, Peh SC, et al. The rapid urease test in the diagnosis of Helicobacter pylori infection. Singapore Med J. 1994 Apr; 35 (2): 161-2.

13. Misra V, Misra S, Dwivedi M, et al. A topographic study of Helicobacter pylori density, distribution and associated gastritis. J Gastroenterol Hepatol. $2000 \mathrm{Jul}$; 15 (7):737-43.

14. Kumar V, Abbas AK, Fausto N, Aster JC. Robbins and Cotran pathologic basis of disease, professional edition e-book. Elsevier health sciences; 2014.

15. Zhang C, Yamada N, Wu YL, Wen M, Matsuhisa T, Matsukura N. Comparison of Helicobacter pylori infection and gastric mucosal histological features of gastric ulcer patients with chronic gastritis patients. World Journal of Gastroenterology: WJG. 2005 Feb 21; 11 (7):976-981.

16. Riddell RH. The biopsy diagnosis of gastroesophageal reflux disease, "carditis," and Barrett's esophagus, and sequelae of therapy. The American journal of surgical pathology. 1996 Jan 1;20:31-50.

\section{How to cite this article?}

Jawahar. R, Varghese R.G.B, Alexander T, Kurian G. Topographic study of H. pylori and gastric intestinal metaplasia in patients with dyspepsia in a tertiary health care setting. Trop J Path Micro 2019;5(5):281-286.doi:10.17511/jopm. 2019.i05.05. 